\title{
ASPECTOS ÉTICOS Y DEONTOLÓGICOS DEL EJERCICIO PROFESIONAL DE LA COMUNICACIÓN CORPORATIVA
}

\author{
Francisco CABEZUELO LORENZO \& Ma José PÉREZ SERRANO \\ Profesores del Departamento de Publicidad, Relaciones Públicas y Marketing de la \\ Facultad de Comunicación de la Universidad San Jorge.
}

\section{Resumen}

En los actuales tiempos de la globalización y la postmodernidad, la relación entre una organización (empresa o institución) y su entorno sólo puede construirse a través de una comunicación veraz y transparente, sistemática y continuada, con los diferentes grupos de interés o stakeholders, que son, en definitiva, los depositarios de la imagen de la empresa, a la vez que sus fiscales. Esta comunicación propone, desde el respeto a los diferentes puntos de vista en las teorías de la responsabilidad social corporativa, el estudio de los modelos de asociacionismo profesional norteamericano con el fin de incrementar en España el interés por los avances en esta materia protagonizados por nuestros colegas anglófonos, que llevan varios años de adelanto en la gestión de la comunicación corporativa.

\section{Palabras clave}

Comunicación corporativa - Ética y Deontología - Códigos de conducta - Relaciones Públicas Asociaciones profesionales - Norteamérica 


\section{Abstract}

In today’s post modern world of globalisation, relations between organisations (private companies or public institutions) and their environment can only be built through transparent and veracious communication. This communication has to be systematic and continuous with its stakeholders, who are in fact the holders of the organisation's image as well as its legal representatives.

This article proposes, with due respect to different positions taken by corporate social responsibility theory, the study of current North American models of professional association, with a view to increasing interest in Spain in the advances made over the past few years in the field of corporate communication in the USA.

\section{Key words}

Corporate Communications - Ethics - Public Relations - Codes - Professionalism - USA

\section{Introducción}

En la actual sociedad postmoderna y globalizada no es usual pararse a pensar en los asuntos relacionados con la Ética de nuestra actividad profesional. A pesar de todo, el tema de la Ética se ha convertido en una preocupación para muchas organizaciones que se han dado cuenta de que el actuar correctamente es indispensable para triunfar y mantener a la organización con vida en entornos cada vez más competitivos. La Ética también afecta a la comunicación corporativa, es decir, a la identidad, a la imagen y a la reputación. Para Aristóteles, nuestra “identidad” proviene de lo que nos entrega la sociedad en la que vivimos y que nos rodea. El filósofo asegura que somos producto de nuestro entorno. Por tanto, en la Ética influyen mucho nuestras tradiciones: aquellas costumbres y hábitos que nuestra sociedad ha ido adquiriendo con el paso del tiempo. A pesar del interés de esta cuestión, desde la óptica de la comunicación en las organizaciones, las investigaciones en este 
campo no son muy numerosas, aunque sí bastante interesantes, recientes y esperanzadoras. Casi todas ellas están basadas en estudios de Responsabilidad Social Corporativa (RSC). Sin embargo, en este artículo, se intenta hacer hincapié no en las buenas prácticas de las organizaciones desde el punto de vista de la RSC, sino en el ejercicio de la labor profesional de los directores de comunicación de las diferentes organizaciones, ya sean éstas públicas o privadas, para lo cual se propone el estudio de los exitosos modelos de las principales asociaciones norteamericanas de profesionales de la comunicación. “La Ética queda establecida por lo que la empresa hace, no por lo que la empresa dice. Es necesario actuar de forma que sirva y que se vea que sirve al bienestar público”, afirma Sam Black (1994:196).

\section{Objetivos}

Al igual que ocurre con muchos planteamientos filosóficos y éticos, este artículo no pretende un estudio material ni cuantitativo de la realidad. Se podría decir que las palabras que siguen a continuación cuentan más con unas metas a largo plazo que con unos objetivos mensurables y cuantificables a corto plazo. El fin de este artículo es hacer reflexionar a los profesionales de la comunicación corporativa sobre unos puntos y cuestiones que suelen pasar desapercibidos: los aspectos éticos y deontológicos del ejercicio profesional de la comunicación corporativa. Por eso, este artículo, tras hacer un repaso a la importancia de la Ética y su justificación en la poliédrica actividad comunicativa de las organizaciones, quiere dar respuesta a los siguientes interrogantes: ¿Podemos considerar el oficio, trabajo u ocupación del comunicador en la Comunicación Corporativa como una profesión homogénea como tantas otras existentes en el mercado de trabajo y reguladas por la ley? ¿Sería necesario que los profesionales para ejercer su trabajo tuvieran que contar con una licencia o estar colegiados? ¿Es imprescindible un documento que nos acredite como profesionales de la comunicación? ¿Unos determinados estudios universitarios serían una garantía de 
la profesionalidad e integridad de los hombres y mujeres que trabajan en el sector? Estos son algunos de los aspectos que hoy en día se debaten nuestros colegas anglófonos, especialmente los norteamericanos, pioneros en materia de Comunicación Empresarial e Institucional, y que, sin duda alguna, se han convertido en aspectos profesionales que también deben ser discutidos en España y en el resto de Europa. Ese es el fin que persigue y pretende cumplir esta breve comunicación: el debate sobre la correcta formación ética de los futuros profesionales de la Comunicación Corporativa. Al mismo tiempo, esta comunicación apuesta por defender el trabajo y honorabilidad de los profesionales de las Relaciones Públicas, ya que, como ha quedado claro, está sobradamente justificado que el profesional de las Relaciones Públicas sea el encargado, en ocasiones, de difundir mensajes e información de tipo persuasivo siempre y cuando la gente, de forma objetiva y razonable, entienda que estos mensajes son persuasivos, pero al mismo tiempo basados en la verdad. También se apuesta desde estas páginas por la implantación de códigos éticos efectivos y reales, no sólo simbólicos o ineficaces.

\section{Metodología}

Con el fin de dar respuesta o provocar la reflexión sobre los aspectos aquí estudiados, este artículo propone una primera aproximación teórica al concepto y al estudio del ejercicio de la comunicación corporativa en la actual sociedad del conocimiento. Posteriormente, pasa a denunciar la falta de unos criterios éticos obligatorios y exige la omnipresencia de unos principios éticos y deontológicos en la profesión. Del mismo modo, propone unas claves propias para una Ética de la Comunicación Corporativa partiendo de la siguiente premisa: si la comunicación corporativa es un instrumento de gestión por medio del cual toda forma de comunicación interna y externa es conscientemente utilizada, con el fin de crear una base favorable para las relaciones con los públicos de los que la empresa depende, el conjunto de actuaciones del profesional de la comunicación debe responder a unas expectativas por parte de los stakeholders, que no pueden sentirse defraudados en la conducta 
de sus interlocutores. No hay imagen sin identidad, pues lo que se comunica no puede ser puro diseño, sino lo que verdaderamente trasciende y comunica es todo aquello anclado necesariamente en la realidad. Es cierto que una marca es una promesa, pero siempre debe ser una promesa basada en la realidad y con motivos más que justificados para atreverse a ligar el producto o servicio que promociona con la realidad. Cualquier otra intervención sería una mentira o tergiversación. Las actuales tendencias de estudios sobre reputación corporativa y también sobre responsabilidad social se fundamentan en el buen hacer y obrar de los miembros de una organización. Finalmente, fiel a la interés y servicio público, este artículo propone el estudio de las organizaciones profesionales norteamericanas de la comunicación y sus códigos éticos, como son la PRSA o IABC, entre otros, para ofrecer un ejemplo de nuestros colegas americanos, que, en este aspecto, vuelven a liderar el mercado y son los auténticos creadores de las teorías de la responsabilidad social corporativa y el resurgir del debate sobre la necesidad de una formación de calidad para los futuros profesionales y el asociacionismo profesional, tan débil todavía en España.

\section{Breve aproximación al concepto y ejercicio de la comunicación corporativa en la sociedad actual}

La comunicación corporativa de una organización y el comportamiento ético de sus miembros son cosas diferentes, pero van de la mano, son interdependientes. La comunicación corporativa, tal y como la entiende Cees B. M. Van Riel es “un instrumento de gestión por medio del cual toda forma de comunicación interna y externa es conscientemente utilizada”. Este instrumento se armoniza tan efectiva y eficazmente como sea posible con el fin de "crear una base favorable para las relaciones con los públicos de los que la empresa depende” (1997:26). Este concepto de comunicación corporativa (corporate comunications), entendido como la gestión estratégica de todos los factores que influyen en la imagen de una organización, ha resumido durante los últimos años en nuestro país 
una visión estratégica de la imagen corporativa cuyo principal objetivo era armonizar las estrategias comunicativas y de negocio de las empresas (Villafañe 2004, 21).

Esta primera aproximación conceptual a la comunicación corporativa ya señala, implícitamente, que una organización, sea del tipo que sea, no podrá tener una buena imagen antes sus públicos y stakeholders por muy buena que sea su identidad, si no la acompaña de buenas acciones, ya que no sólo el diseño comunica. Comunican también todas y cada una de las acciones de los miembros de una empresa o institución. Igual que Norberto Mínguez (1999) afirma que "los conceptos de identidad e imagen corporativa son interdependientes” y que "no hay imagen sin identidad, pues lo que se comunica no puede ser puro diseño, sino que ha de estar anclado necesariamente en la realidad”, este artículo reivindica la coherencia entre la identidad corporativa de las organizaciones y el comportamiento ético de sus miembros en la toma diaria de decisiones. Por eso, tampoco es difícil coincidir con Mínguez cuando señala que "la imagen corporativa no atañe exclusivamente al departamento de comunicación, sino que es una tarea que afecta a la alta dirección y su gestión exige el compromiso de las distintas áreas funcionales de la organización y, en última instancia, de todos y cada uno de los empleados de la empresa”. Efectivamente, una imagen y una reputación positivas no son sólo el resultado de una buena comunicación, sino de una actividad conforme a lo que esperan los públicos de una organización.

Aunque la comunicación corporativa es hoy en día algo vital, no es el único elemento que aportará una buena reputación a la organización. Las empresas e instituciones deben hoy gestionar de forma eficaz y sistemática todos sus activos, con especial hincapié en aquellos que una vez que se pierden no se puede recuperar con facilidad. Como afirma Mínguez, "la imagen debe gestionarse en todos los niveles de la organización y en todas las áreas de su actividad, pues el comportamiento de la empresa, cada acto de cada uno de sus empleados, tiene un efecto en su imagen global”.

Llegamos a otra nueva realidad actual: la etapa de los estudios de reputación corporativa. Se entiende por “reputación corporativa” la expresión de la identidad de la organización y del 
reconocimiento de su comportamiento corporativo. Para Justo Villafañe (2004:29), la identidad corporativa es la síntesis de la historia de la organización, de su estrategia o proyecto empresarial vigente y de su cultura corporativa. Desde esta perspectiva, para este autor, la noción de identidad es sinónimo de realidad corporativa y la reputación tiene “su origen en la realidad de la empresa y, más concretamente, en su historia, en la credibilidad del proyecto empresarial vigente y en la alineación de su cultura corporativa con ese proyecto”. Así, Villafañe define la reputación como "la cristalización de la imagen corporativa de una entidad cuando ésta es el resultado de un comportamiento corporativo excelente, mantenido a lo largo del tiempo, que le confiere un carácter estructural ante sus stakeholders estratégicos” (Villafañe 2004:32).

Esta comunicación corporativa que persigue la buena reputación no es un concepto abstracto. Por el contrario, el ejercicio de las acciones de comunicación corporativa lo desarrollan a diario miles de profesionales de todo el mundo bajo las órdenes de los directores de comunicación de las empresas o instituciones para las que trabajan. ¿En qué consiste esa dirección de comunicación? Rex Harlow, fundador de la Public Relations Society of America (PRSA) allá por el año 1947, definió la dirección de comunicación y relaciones con los públicos como la gestión de una actividad específica que ayuda a establecer y mantener líneas mutuas de comunicación, comprensión, aceptación y cooperación entre una organización y sus públicos.

La dirección y gestión de la comunicación se ha convertido hoy en día en uno de los campos con mayor éxito en la actual sociedad del conocimiento. Las autoridades norteamericanas, tan dadas ellas a calcular todo y sacar cifras y estadísticas de todo tipo estiman, que en la actualidad 200.000 personas trabajan en este campo tan sólo en Estados Unidos, donde el sector de las Relaciones Públicas mueve cada año un total de 141.000 millones de dólares. Afirman también que en total, en todo el planeta, hay más de tres millones de personas que se dedican, como principal trabajo a la Comunicación y las Relaciones Públicas (Wilcox, 2005: 3), de los que poco más de una décima parte, unos 360.000, pertenece a una organización profesional. 


\section{Planteamientos éticos en la sociedad de la información y el conocimiento}

Es muy difícil poder determinar con claridad hacia dónde nos lleva la actual realidad postmoderna. Tras finalizar el siglo XX, huérfanos de líderes tan grandes como desastrosos o alejados de los históricos planteamientos políticos de izquierda y derecha, los actuales movimientos filosóficos postmodernos son herederos de diferentes pensadores y tendencias. Ahora que los discursos intelectuales y políticos han perdido credibilidad, nuestro mundo postmoderno sufre un proceso de “atomización”. Así, parece que los actuales planteamientos éticos en nuestra sociedad de la información y el conocimiento se sitúan a caballo entre el escepticismo de algunos autores griegos de la Antigüedad y el saludable pragmatismo aristotélico, por lo que algunos autores se atreven a afirmar que hoy la mayor parte de los ciudadanos occidentales dudemos de quienes declaran que la verdad existe y afirman tener vinculación directa con ella.

Las pistas parecen ir por otros derroteros. En el siglo XX, tras grandes fracasos históricos, heredamos, sin embargo, algunos valores positivos, como aquellos lanzados por los movimientos de preocupación por la cuestión de nuestra relación con el entorno natural. Parece que ahora más que nunca somos conscientes de que la industrialización salvaje y desordenada puede amenazar con hacer insostenible el actual nivel de desarrollo de las sociedades occidentales y de casi todo el planeta. En este contexto, el ser humano lucha por encontrar nuevas ideologías políticas, económicas y culturales, que sean alternativas a las tradicionales con el fin de preservar el entorno. De este modo, se puede llegar a afirmar que la tendencia actual acostumbra a ligar los estudios de comportamiento del ser humano con su entorno.

Ya en la Antigüedad, Aristóteles denominaba al ser humano como un “animal político”. Los seres humanos somos seres sociales por naturaleza. Necesitamos de los demás. Necesitamos de la comunicación. Para Aristóteles, nuestra “identidad” proviene de lo que nos entrega la sociedad en la 
que vivimos y que nos rodea. Aristóteles asegura que somos producto de nuestro entorno. Los seres humanos somos extraordinariamente gregarios. La vida comunitaria se sustenta en tradiciones y en valores que los grupos entregan a sus miembros. Aristóteles proponía que se debe incentivar actitudes positivas hacia otros, luego, el comportamiento ético se volverá instintivo, independiente de reglas o sistemas. Por tanto, en la Ética influyen mucho nuestras tradiciones, aquellas costumbres y hábitos que nuestra sociedad ha ido adquiriendo con el paso del tiempo. Filósofos anteriores como Platón ya habían descrito la preocupación existente por ese entonces sobre algunos asuntos morales en el Mundo Antiguo, sentando, de este modo, las bases de lo que actualmente denominamos el “análisis ético”. Platón ya era consciente de que todos tenemos nuestras propias ideas de lo que es “bueno” y lo que es “malo”.

Los tiempos cambian y muchos autores se lanzar a afirmar hoy que la Ética de la Comunicación se encuentra en una encrucijada. Por tanto, la pregunta es: ¿Deben cambiar nuestros principios éticos en la actual sociedad de la información y el conocimiento? ¿La Ética se adapta a los tiempos? Sin duda alguna, los valores y criterios directores de nuestras actuaciones tienen que adaptarse a los tiempos. Nuestros valores y criterios se ven afectados en cierta forma por la evolución de los propios conocimientos que tan rápidamente se propagan gracias a las nuevas tecnologías de la actual sociedad de la información. Sin embargo, esta evolución no significa que todo esté cambiando constantemente en el campo de la Ética ni que estos valores puedan ser “relativizados”.

Algunos autores, como F. Enebral Casares (1995), nos recuerdan que los criterios encuadrados en la Ética pretenden “el mejor, más auténtico y más sostenido modo de regular las interacciones que están teniendo efecto en un grupo por la vitalidad de sus componentes”. Se entiende, por tanto, que hay un ánimo axiomático que seguirá siendo siempre válido en toda circunstancia, es decir, la Ética ha estado, está y estará ahí para intentar mejorar, hacer más auténtico, sostenido y eficaz el modo de regular las interacciones que tienen lugar entre los 
diferentes miembros de un grupo. Ése es el fundamento permanente y siempre válido de la Ética. Así, se puede afirmar que las manifestaciones concretas de ese principio inspirador y fundamental de la Ética pueden y deben ir adaptándose a las propias interacciones a las que se aplique. Enebral Casares (1995) nos recuerda también que “cuando la Humanidad se restringía a grupúsculos tribales, la Ética en ellos tenía expresiones apropiadas a su nivel de conocimientos y de la complejidad social de su civilización. Pero, cuando éstos varían, aumentan, y se enriquecen con nuevas y múltiples facetas, la Ética deberá proponerse abarcar estos nuevos aspectos de una manera coherente con el caudal de conocimientos que ahora se tengan sobre la propia complejidad que manifiesta la convivencia”. Hoy vivimos en la sociedad de la información y del conocimiento, de las nuevas tecnologías, por lo que la Ética exige una aplicación determinada.

La Ética en sí misma está siempre en continúa evolución en tanto en cuanto se está desarrollando y poniendo en práctica constantemente, pero eso no significa que sea un “valor relativizado”. Dicho de otro modo, la Ética está en evolución, pero no los principios que la inspiran, es decir, mantiene su eje axiomático consistente en mejorar, autentificar y garantizar el sostenimiento de las interacciones justa y eficazmente. Esos principios han sido, son y serán siempre válidos, e inspiradores a su vez de cada uno de los desarrollos que adquiera su adecuación a los nuevos eventos en los que se aplique.

De este modo, no podemos decir que debido a los cambios en esta sociedad, cada vez más compleja, y especialmente en las interacciones que en ella se producen, la Ética ya no existe o ha desaparecido. Nunca podrá decirse que la Ética está en crisis, al menos si entendemos como tal la exigencia connatural de la inteligencia humana para procurar gobernar mejor el entorno en el que vive. Lo que si es cierto, como afirman Elzaburu y Martitegui (1988), es que han cambiado las aplicaciones que se hacen de la Ética. Es decir, han cambiado el conjunto de criterios referenciales de segundo orden, más pragmáticos, y más circunscritos a determinadas perspectivas. Estos criterios sí pueden estar en crisis y pueden necesitar una renovación o actualización drástica. Hoy en día, el 
lado más pragmático e inmediato de la Ética no podría ser probablemente entendida en otro contexto temporal.

Esta necesidad de contar con unos principios éticos, además de con unos valores en la profesión, resulta particularmente interesante en uno de los campos de especialización de la comunicación aplicada, como es el caso del ejercicio profesional de la Comunicación Corporativa. ¿Qué supone todo esto para el profesional de la comunicación? Sin duda alguna, significa una mayor e ineludible exigencia ética en los profesionales de la comunicación, en especial en la Comunicación Corporativa, y, sobre todo, en formadores de futuros profesionales de la comunicación. Es obvio que todos tenemos una responsabilidad fruto de la trascendencia y relevancia de nuestro trabajo. Hoy es especialmente necesario subrayar la necesidad de dar una mayor importancia a la Ética en la formación de los futuros profesionales de la comunicación empresarial e institucional, ya que la Ética es una faceta imprescindible en todo comunicador y un aspecto cada vez exigido por las empresas, los públicos, clientes, y la sociedad en general.

\section{La ética de la comunicación corporativa}

A la hora de hablar de los aspectos éticos de la comunicación corporativa, Joan Costa habla del “lenguaje de los actos”. Para el autor catalán este lenguaje corporativo debe guardar una coherencia necesaria y obligatoria con el resto de mensajes que la organización intercambia con sus stakeholders. Este lenguaje de los actos se basa en la convicción, el compromiso y la autorregulación de todos los integrantes de la organización. En el caso de las grandes organizaciones, como pueda ser el caso de las gigantes y omnipresentes empresas multinacionales, esos grupos de interés están conformados principalmente por los accionistas, los inversores, los mercados financieros en los que cotizan sus acciones y los organismos reguladores. También podemos incluir el propio personal y sus familias, contemplados no sólo en su relación directa con la empresa sino también en sus respectivos ámbitos sociales. Por supuesto, no pueden faltar los clientes, consumidores o usuarios ni 
los proveedores. En esas empresas, caracterizadas por su compleja organización y diversidad de públicos, la comunicación con cada uno de esos segmentos constituye en sí misma una especialidad necesariamente a cargo de distintas áreas y departamentos, pero siempre con una toma de decisiones que tenga como paraguas común la Ética y Deontología profesional de la Comunicación.

La cuestión de la Ética en la comunicación corporativa no es, ni más ni menos, que una pequeña parte de un tema más amplio: el de la Ética de los negocios y el comportamiento ético en la actual sociedad postmoderna. Aunque la mayoría de las empresas e instituciones son muy celosas de su reputación y se toman mucho interés en protegerla de cualquier daño o crítica, no hay más que repasar algunos hechos recientes que confirman que no todas las empresas actúan correctamente. Estos casos destacan la necesidad de mantener un comportamiento ético. El escándalo protagonizado en los EEUU por la empresa Enron, del que la inmensa mayoría de la opinión pública, tanto en su país como en el resto del mundo, difícilmente puede recordar quiénes fueron los culpables, dañó seriamente la imagen de esa gran corporación, comprometiendo su reputación hasta tal punto que obligó a la empresa auditora involucrada a cambiar su denominación. Como contrapartida, cabe decir que, a consecuencia de ello, el caso despertó el interés de las escuelas de negocios norteamericanas en el nuevo concepto de la responsabilidad social empresaria como un factor de vinculación de las decisiones de negocios con valores éticos y respeto a la comunidad como forma de ganar la preferencia del público. Pero Enron no fue el único de los escándalos provocados por la falta de Ética de algunos de sus responsables. Tenemos también los casos de Xerox, WorldCom, Martha Stewart’s Omnimedia, en Estados Unidos; Société Genérale, en Francia, o Parmalat, en Italia. En el caso de España, podemos citar los fraudes financieros de Gescartera, Eurobank, o Afinsa-Fórum Filatélico, entre otros. Si los responsables de estas empresas hubieran mantenido un comportamiento ético no habría pasado lo que pasó. Recientemente se han producido todos estos escándalos a los que los medios de comunicación han dado amplia cobertura y que han provocado que mucha gente tenga dudas sobre la integridad de los profesionales. Estos ejemplos nos ponen 
claramente de manifiesto que los principios morales generales son cercanos a la rutina diaria de los comunicadores, de su forma de trabajar en las empresas, lo que lleva a afirmar a algunos autores como Sam Black (1993:195) que "la declaración de objetivos de una empresa debería proporcionar una orientación sobre qué tipo de comportamiento ético es obligatorio dentro de la organización” y que "el concepto de valores éticos y morales en una empresa debe proceder de lo alto e irse reflejando hasta llegar a lo más bajo”. Sin duda alguna, la cuestión de la Ética en la comunicación es una preocupación de vital importancia para aquellos profesionales de la comunicación corporativa que trabajan día a día por lograr la mejor aceptación y apoyo del público para sus organizaciones. Los valores morales y éticos no son siempre absolutos. Además, su articulación en cualquier empresa o institución estará relacionada, en todo momento, con la cultura corporativa de la organización, pero no lo puede estar por las campañas o estrategias varias y sus tácticas, que buscan conseguir objetivos a corto plazo.

Algunos autores, como Kenneth Blanchard y Norman Vincent Peale, abogan por un conjunto de cinco valores que denominan los 'Principios del Poder Ético' que toda empresa o institución debe mantener si quiere conseguir y perpetuar una equilibrada comunicación corporativa. 


\section{Los principios del Poder Ético en las organizaciones de Kenneth BLANCHARD \& Norman V. PEALE}

1.- Propósito.- La misión de nuestra organización se comunica desde la cumbre. Nuestra organización está guiada por los valores, esperanzas y una visión que nos ayuda a determinar qué tipo de conducta es aceptable o inaceptable.

2.- Orgullo.- Estamos orgullosos de nosotros mismos y de nuestra organización. Sabemos que cuando nos sentimos así, somos capaces de resistir la tentación de comportarnos de una forma no Ética.

3.- Paciencia.- Creemos que si nos atenemos a nuestros valores éticos, esto nos conducirá al éxito, a largo plazo. Esto implica que hemos de mantener un equilibrio entre la obtención de resultados y preocuparnos del modo en que los conseguimos.

4.- Persistencia.- Nos hemos comprometido a vivir según los principios de la Ética. Estamos comprometidos con nuestro compromiso. Nos aseguramos de que nuestros actos estén de acuerdo con nuestro propósito.

5.- Perspectiva.- Nuestros directores y empleados se toman tiempo para pararse y empleados se toman un tiempo para pararse y reflexionar, darse cuenta de dónde estamos, evaluar hacia dónde vamos y determinar cómo vamos a llegar allí.

Por su parte, el profesor Frank Wylie (California State University) afirma que, en la Ética de la comunicación corporativa, hay dos grandes ejes deontológicos. Por un lado, señala la responsabilidad de cumplir nuestros deberes de una forma ética, y por otro, la responsabilidad de cumplir nuestros deberes de una forma capaz. A pesar de establecer estas dos pautas, Wylie considera que estas pautas no son suficientes para obtener la excelencia en los resultados desde el punto de vista ético. Por su parte, Melvin Sharpe (Ball State University of Indiana), tras una profunda reflexión, se formula unas pautas para comunicar de forma ética y profesional. Sharpe afirma que toda organización debe:

a) Comunicar honestamente con el fin de obtener credibilidad.

b) Ser abierta y consistente en todas sus acciones con el fin de obtener la confianza del público.

c) Mantener la imparcialidad y equidad en sus actos con el fin de ofrecer un trato justo.

d) Mantener una comunicación continua con el fin de que lograr respeto y comprensión mutuos.

e) Investigar de forma adecuada su entorno social con el fin de comunicar sus posturas de una forma más eficaz y que cambie sus acciones, cuando éstas ya no sirvan al interés público. 
Sharpe también considera que las decisiones tomadas a escondidas, aunque procedan de la Ética, llevan la mancha de la desconfianza. La realidad y la imagen deben entrelazarse; no sólo debe hacerse justicia, debe verse que se hace. Este aspecto es de una importancia vital para la comunicación corporativa.

\section{Las asociaciones profesionales norteamericanas de la comunicación y sus códigos deontológicos}

En algunos países de nuestro entorno, especialmente en aquellos más avanzados en materia de comunicación, existen, desde hace muchos años, organizaciones profesionales que pueden ser muy útiles para orientar en su trabajo diario a los profesionales de la comunicación. En España, cada vez más, surgen varias iniciativas de este tipo, con el fin de defender los derechos de estos colectivos. Este artículo propone una revisión de las posturas de las principales asociaciones profesionales internacionales en las que se agrupan miles de profesionales de la comunicación para extraer unas conclusiones y pautas claras que sirvan para crear una Ética propia de la Comunicación Corporativa. The Public Relations Society of America (PRSA), The Institute of Public Relations (IPR), The International Association of Business Communication (IABC) son algunas de las asociaciones aquí analizadas.

The Public Relations Society of America (PRSA) es la asociación de Relaciones Públicas más grande de todo el mundo. Tiene su sede en Nueva York y cuenta con nada más y nada menos que más de 20.000 miembros repartidos en un total de 116 delegaciones en todo el territorio estadounidense. A su vez, se divide en 18 secciones profesionales que van desde el área de negocios e industria, hasta firmas como consultoras, profesionales independientes, organizaciones sin ánimo de lucro, instituciones académicas y un largo etcétera. Celebra una importante reunión o conferencia anual y saca a la luz dos publicaciones, una titulada 'Tactics', un tabloide mensual con información sobre la profesión, y 'The Strategist', una revista que analiza más en profundidad los cambios en la 
práctica de las Relaciones Públicas. La PRSA basa sus valores profesionales en el buen consejo, la honestidad, la experiencia, independencia, lealtad y rectitud de sus miembros, e invita a sus miembros a servir al interés público, ofreciendo una sola voz para un debate de ideas bien informado. Busca la adhesión de sus miembros a los más altos estándares de exactitud y veracidad para servir, así, provechosamente a los intereses de sus clientes y a la comunicación con sus públicos y audiencias. El código ético propuesto por la PRSA se basa en seis valores que considera “vitales para la integridad de la profesión en su conjunto” y afirma que “el valor de la reputación de los socios depende de la conducta ética de cada afiliado de la PRSA". "Cada uno de nosotros es un ejemplo para los demás, así como para otros profesionales, al procurar excelencia en nuestra labor con intensas normas de desempeño, profesionalismo y conducta ética”, añade su código. La PRSA invita a servir al interés público, ofreciendo un debate de ideas bien informado adhiriéndose a los más altos estándares de exactitud y veracidad para los intereses de sus clientes y la comunicación con el público, al tiempo que generan un entendimiento mutuo en la actual sociedad del conocimiento. Los valores defendidos por la PRSA son los siguientes:

Advocacy. Se puede entender como apoyo, como consejo, como servicio, servir el interés público actuando como defensores responsables de los posibles clientes o trabajadores.

Honesty. Se piden los más altos estándares de calidad, de verdad, de honestidad y honradez, por el máximo interés de clientes y empleados, también.

Expertise. La experiencia se considera una herramienta para avanzar en el camino de la profesionalidad, de la especialización, de la investigación, y de una mejor calidad en los servicios prestados.

Independence. Se entiende como independencia que el profesional debe atender al cliente facilitándole el análisis más independiente y justo posible.

Loyalty. Se trata de la lealtad y fidelidad a los fines perseguidos y al cliente por el que se trabaja, sin olvidar nunca el bien común. 
Fairness. Se refiere a la rectitud y a la necesidad de justicia, equilibrio y equidad, de respetar todas las opiniones y apoyar la libertad de expresión.

En el caso de la RPSA, a pesar de que en teoría es uno de los mejores cuadros para orientar la profesión, encontramos que, a pesar de los numerosos escándalos, su estricto cumplimiento ha quedado bastante limitado. Así, por ejemplo, encontramos que desde 1990 a 1998 ningún miembro de la PRSA fue recriminado por acción alguna, ni menos expulsado o suspendido de la asociación. Por último, esta comunicación no quiere terminar sin hacer una mención más a la importancia que la Ética está tomando en nuestro país en el desarrollo de la actividad profesional y económica, destacando la implantación de varias ideas norteamericanas y europeas en nuestro territorio, como es el caso de la certificación ética.

La segunda gran asociación de los profesionales de la comunicación es The International Association of Business Communicators (IABC). Tiene su sede en San Francisco (EEUU). Cuenta con más de 13.000 miembros distribuidos a lo largo de más de 60 países. Aunque la mayoría de ellos están en Estados Unidos, cuenta con secciones muy importantes en Canadá, Reino Unido y Hong Kong. La IABC de Toronto, en Canadá, cuenta con más de 1.300 socios, lo que supone el 10 por ciento del total de la organización. Entre las actividades de la IABC destaca la publicación de la prestigiosa revista 'Communication World', en la que analiza en profundidad algunos casos prácticos e informa de las últimas novedades en el sector. Su código se basa en tres principios que vienen a decir que la comunicación profesional debe ser, ante todo, legal, ética, y de buen gusto.

The Internacional Public Relations Association (IPRA) es la tercera organización profesional más importante en el campo de las Relaciones Públicas. Es también anglosajona, pero escapa ya de Norteamérica. La IPRA tiene su sede en Londres (Reino Unido) y cuenta con más de 1.000 miembros repartidos en un total de 96 países por todo el mundo. La mayoría de sus miembros podrían ser definidos como “senior international public relations executives”. Su publicación principal lleva por título 'Frontline’. 
PRSA, IABC e IPRA son las organizaciones que abarcan a un mayor número de profesionales, pero hay otras tantas entidades bastante importantes y que han ejercido un papel destacado en la implantación de códigos éticos entre los norteamericanos. Es el caso de The Council for the Advancement and Support of Education (CASE), The National Investor Relations Institute (NIRI), y The National School Public Relations Association. Dada la fuerte y creciente presencia hispana en EEUU, cada día es más importante el papel de algunas pequeñas organizaciones de lengua española. Tal es el caso de la Asociación de Relacionistas Profesionales de Puerto Rico.

Sin duda alguna, una de las cosas que primero llama la atención al estudiar la Ética aplicada a la Comunicación en EEUU es el uso de los nombres, es decir, la terminología. La propia forma de referirse a los códigos como (codes of conduct) en vez de “código ético o deontológico” ya nos da una muestra más del pragmatismo norteamericano. Prácticamente, cada asociación tiene su propio código, siendo especialmente conocidos los de las organizaciones anteriormente citadas, y la mayoría de ellas se reserva el derecho de criticar, censurar, o expulsar de su seno a quien no cumpla con estos códigos.

La PRSA, por ejemplo, en su más de medio siglo de historia sólo ha ejercido este derecho en diez ocasiones. El código de la IABC hace un especial hincapié en subrayar el principio de que el profesional de la comunicación debe ir más allá de lo legal y lo ético, debe también apostar por el buen gusto y los valores y creencias culturales más decorosas. IABC basa sus principios en la legalidad, la ética y el buen gusto, en un código de doce artículos en los que se subraya la necesidad de que los profesionales practiquen una comunicación honesta, verdadera y plural, al promover la libre circulación y flujo de información y contenidos de acuerdo con el interés general del público. Esta organización también pone énfasis en el compromiso de los profesionales con la verdad y la libertad de expresión, además del respeto por la legalidad vigente. Igualmente presta especial atención al respeto a los valores y creencias culturales, el pluralismo. También alienta la corrección 
de errores detectados, a la vez que exige confidencialidad de la información a la que tienen acceso por su actividad.

Al mismo tiempo, estos códigos de conducta norteamericanos, en algunas ocasiones, llegan a establecer cuestiones tan puntuales como es, por ejemplo, cómo tratar un “vídeo-comunicado”, en América llamados “video news releases” (VNRs). ¿Está bien que un medio de comunicación use imágenes un vídeo-comunicado que le ha sido facilitado por una empresa con unos intereses concretos? Seis productores (Wilcox, 2006:83) norteamericanos de televisión, miembros del Public Relations Council de Nueva York, acordaron que sí, siempre y cuando:

- la información sea verdad, que no se trate de contenidos falsos.

- el vídeo-comunicado sea identificado como tal, es decir se cite la fuente.

- la cinta haya sido facilitada por alguien identificable, saber el origen.

- las personas que aparezcan en el mismo deben estar identificadas y no pueden ser personajes ficticios, es decir, no se puede vender ficción como realidad.

Pero, en Norteamérica, no son sólo las grandes asociaciones cuentan con interesantes códigos de los que todos podemos aprender. Las grandes firmas de Relaciones Públicas también hacen públicos sus códigos. Así, la agencia Ketchum, la gran firma de Comunicación y Relaciones Públicas que cumple ahora 80 años, tiene su propio código en el que pide, entre otros puntos:

- Respeto absoluto a la verdad.

- Uso correcto de la información confidencial.

- Detalla qué regalos e invitaciones para espectáculos son aceptables y no.

- Trato justo con clientes y trabajadores.

- Salvaguardar la propiedad de la información de los clientes.

- Evitar “abusos” vinculados a la posesión de una determinada información.

El caso por ejemplo del abuso de información, uso de información privilegiada y temas paralelos tiene una gran trascendencia en EEUU, como ha demostrado en los últimos meses (F. 
Cabezuelo \& I. Rodríguez, 2005) el caso de la famosa comunicadora y empresaria Martha Stewart, una de las mujeres más famosas del país y poseedora de una las grandes fortunas del mundo, recientemente en libertad tras pasar cinco meses en la cárcel por abuso de información privilegiada en la venta de acciones de una compañía.

\section{Conclusiones}

Las empresas e instituciones no son, ni más ni menos, que entes formados por un conjunto de personas. Las organizaciones son, por tanto, entes neutros. De este modo, no son morales ni inmorales, más bien podemos decir que son amorales, pero sí puede ser moral o inmoral el comportamiento de sus miembros que, en ese momento, son identificados con la corporación a la que representan. "La Ética queda establecida por lo que la empresa hace, no por lo que la empresa dice. Es necesario actuar de forma que sirva y que se vea que sirve al bienestar público”, afirma Sam Black (1994:196). Por eso, los profesionales de la comunicación corporativa deben entender el valor real y significado del ejercicio profesional conforme a unas pautas, lo que sin duda alguna redundaría en beneficio de la Ética. Por eso, desde las páginas de este artículo se recomienda la autorregulación profesional a través a asociaciones e institutos profesionales, como conclusión principal de este trabajo. De todos modos, junto a esta conclusión, añadimos otras:

1. Los últimos casos de corrupción, falsedad o fraude, en los que se han visto involucrados grandes grupos económicos y profesionales tiempos ponen de manifiesto, además de la necesidad de mantener las exigencias éticas, especialmente en el campo de la Comunicación Corporativa, Institucional y Relaciones Públicas, la necesidad de cuestionarnos la importancia de los valores éticos en el trabajo diario. La Comunicación Corporativa, tanto en Norteamérica como en Europa, debe encontrar en la Ética el eje del ejercicio de la actividad profesional de forma que los códigos no suplanten a las instancias jurídicas, ni supongan una autocensura, pero que sí cuenten con la fuerza suficiente como poder fiscalizador efectivo que colabore notablemente con mejorar la buena 
reputación de un sector en auge y responsable como son las Relaciones Públicas. Hoy, los profesionales de este sector en España y en el mundo tenemos la responsabilidad de transmitir una información verídica y honesta que ayude a la opinión pública a tomar decisiones acertadas.

2. Las organizaciones, ya sean empresas o instituciones, deben ir más allá de los derechos y obligaciones que les corresponden como entes jurídicos. Además de cumplir con los fines específicos para los que fueron creados, también pueden ir más allá y desarrollar su actividad como ciudadanos corporativos comprometidos con la comunidad que les rodea o en la que desarrollan su actividad. Esta relación define los alcances de su responsabilidad social a partir del presupuesto único de una conducta ética basada en una clara enunciación de principios y valores compartidos por toda la organización, y en el ejercicio de la autorregulación como guía de su forma de proceder en todos los aspectos.

3. Para terminar, no podemos dejar pasar otros puntos de interés en la formación de los futuros profesionales del sector de la Comunicación que el día de mañana tendrán que implementar estrategias, tácticas y herramientas de comunicación corporativa sin hacernos unas cuantas preguntas. Debemos cuestionarnos más a menudo sobre los aspectos éticos, deontológicos y profesionales de la Comunicación y el Marketing. A menudo, pensamos sólo en la eficacia y la rentabilidad, fruto de nuestra mentalidad productiva. En Norteamérica, esa parte del mundo tan criticada por su mentalidad de consumo, se habla más de ética que en Europa y se usan permanentemente estos términos cuando se habla de buenas prácticas en materia de Marketing, Comunicación Corporativa y RRPP. Las compañías americanas dedican más a causas sociales que las europeas y los profesionales americanos han estado otra vez más atentos a temas de Responsabilidad Social Corporativa. También han sido los primeros en crear asociaciones profesionales. En ese sentido, nosotros somos más liberales y menos organizados. Pero, ¿qué es mejor? ¿Podemos considerar que el profesional que se dedica al Mix de Comunicación ejerce una profesión con una actividad homogénea como tantas otras existentes en el mercado de trabajo y 
reguladas por la ley? ¿Sería necesario de los profesionales para ejercer su trabajo tuvieran que contar con una licencia, permiso o número de colegiado? ¿Es necesario un documento que nos acredite como profesionales de la Comunicación? ¿Sería una garantía de la profesionalidad e integridad de los hombres y mujeres que trabajan en el sector?

Estos son algunos de los aspectos que hoy en día se debaten nuestros colegas norteamericanos y anglófonos, sociedades pioneras en la puesta en marcha de ese famoso Mix, y que, poco a poco en España se estudian del mismo modo, debido al mundo globalizado que compartimos. Sin duda alguna, todas estas cuestiones se han convertido en aspectos profesionales que también deben ser discutidos en España y en el resto de Europa. Un primer paso en esta línea, es el fin que persigue este trabajo: el debate sobre la correcta formación ética de los futuros profesionales de la comunicación corporativa.

\section{Bibliografía}

- BLACK, S. (1994). ABC de las Relaciones Públicas. Gestión 2000. Barcelona.

- CABEZUELO, F. (2007). Cruïlles de l'Etica en la actual societat del conexeiment. Revista Trípodos. F. Blanquerna. Universistat Ramon Llull. Barcelona. Mayo. Núm. Extra.

- CABEZUELO, F. \& RODRÍGUEZ, I (2005). Falsedad y Comunicación en los medios norteamericanos: el caso de Martha Stewart. Seminario sobre Excelencia en Comunicación “Falsedad y Comunicación: Información falsa, imagen manipulada y publicidad engañosa”. Universidad de Málaga. Noviembre, 2005.

- ENEBRAL CASARES, F. (1992). La información interactiva en gabinetes de comunicación. Tesis doctoral. Universidad Complutense de Madrid.

- MÍNGUEZ, N. (1999). Un marco conceptual para la comunicación corporativa. Revista ZER. Universidad del País Vasco. Núm. 7. Diciembre de 1999.

- SHARPE, M. (1990). Internacional Public Relations Review. Vol. 13. Núm. 3. Págs. 21-25. 
- VAN RIEL, C. B. M (1997). Comunicación Corporativa. Prentice Hall. Madrid.

- VILLAFAÑE, J. (2004). La buena reputación. Claves del valor intangible de las empresas. Editorial Pirámide. Madrid.

- WILCOX, D., \& CAMERON, G. (2006). Public Relations: Strategies and Tactics. 8th edition. Boston. Allyn and Bacon.

- WYLIE, F. (1991). Public Relations Quartely. Ed. Verano. Págs. 7-13. 